\title{
Brands as personal narratives: learning from user-YouTube-brand interactions
}

\author{
Hemant C. Sashittal ${ }^{1}\left[\right.$. Avan R. Jassawalla ${ }^{2}$
}

Revised: 22 June 2021 / Accepted: 1 August 2021 / Published online: 21 August 2021

(c) The Author(s), under exclusive licence to Springer Nature Limited 2021

\begin{abstract}
This paper reports a three-stage study of user-brand interactions on YouTube. An initial exploration identified unique, previously unknown, constructs active in this context. Grounded hypotheses and scales were tested via two surveys separated by approximately 15 month; first survey taken pre-Covid was followed by a second survey in May 2021 (Covid-vaccine present environment). We report that YouTube usage is significantly shaped by feelings of social dread; users find comfort and fall into a YouTube rabbit hole, which leads them to a self-construal. Rooted in cognitive and emotional processes of self-construal, brands emerge as personal narratives. These narratives help users understand their history and personality; they provide a compelling basis for relating with others. The study produces new implications for future branding theories and practice reflective of the emerging reality of user-brand interactions on YouTube.
\end{abstract}

Keywords Brands as personal narratives $\cdot$ YouTube users $\cdot$ Social dread $\cdot$ Rabbit holing $\cdot$ Comfort finding

\section{Introduction}

Branding literature is rich with insights into the characteristics consumers attribute to brands (Holt, 2002; Thomson et al., 2005). Much is known about attributions of personalities (Aaker 1996), or human-likeness (Aggarwal and McGill 2007; MacInnis and Folkes 2017), or coolness (Warren, et al. 2019), or love (Batra et al. 2012), hate (Kucuk 2019; Zarantonello et al. 2016), or vulgarity to brands (Griffiths 2018). User-brand interactions on social media are similarly triggering new attributions; e.g., on Twitter, brands are celebrities (Sashittal and Jassawalla 2019a), on Snapchat they are friends and acquaintances (Sashittal and Jassawalla 2019b), and on Instagram they are tribal-artifacts (Sashittal and Jassawalla 2020). The literature is silent, however, when it comes to explaining brand-related attributions that emerge as a result of YouTube usage (see Vander Shee et al. 2020). This gap in theory is substantive and consequential; YouTube has over two billion users a month and has emerged as

Hemant C. Sashittal

sashi@sjfc.edu

1 School of Business, St. John Fisher College, Rochester, NY 14618, USA

2 School of Business, State University of New York at Geneseo, Geneseo, NY 14454, USA the second most popular search engine (Funk 2020; Omnicore 2021).

Our purpose here is to address this gap and report findings from a three-stage study that examined brand-related attributions resulting from user-brand interactions occurring on YouTube. The first stage of our study began in October 2019. We explored how and why YouTube using college students interacted with brands on YouTube, and generated grounded theory. The research questions guiding the study were: (a) how do YouTube users describe their interactions with brands on YouTube, and (b) what do they identify as the antecedents and consequences of their interactions with brands on this medium. The measurement scales of newly identified constructs and hypothesized relationships were initially tested via a survey conducted in February 2020 (preCovid-19 pandemic). By the time the first-stage data analysis was completed in early April 2020, much of the global economy was under transition as a result of the Covid pandemic. Hence, we collected survey data from a second nationwide sample in early May 2021, at a time when the supply of Covid-vaccines in the US began to exceed the number of adults willing to vaccinate. This second sample attested to the robustness of findings from the pre-Covid study.

Our studies make the following contributions to future branding theory and practice. First, it is one of the few studies in branding research that develops grounded theory, 
identifies new constructs or an ontology unique to the user-brand-YouTube interactive context, derives and tests new measurement scales, and presents evidence to support hypothesized relationships that are robust despite significant Covid-19 triggered changes in American social-psychology. Second, aligned with our exploratory intent, we identify new constructs, or a new ontology of future branding theories devoted to understanding user-brand interactions on YouTube, including social dread, comfort finding, rabbit holing, and brands as personal narratives. In so doing, we present evidence that YouTube usage triggers a self-construal; users employ brands to understand their own personality and history, and develop compelling narratives about themselves to enrich their social relationships. Finally, we present evidence from two surveys taken across a 15-month period-from pre-Covid to vaccine-present environments-to test the robustness of scales and proposed relationships when the social-psychology and behaviors of American consumers were otherwise changing in significant ways.

\section{Conceptual background}

The user-YouTube-brands interactive context is substantive to merit distinct theory development; it has emerged as the second most popular search engine with 3 billion searches and 1 billion unique visitors per month. Started in 2005 by former PayPal employees, and purchased by Google in 2006 for $\$ 1.65$ billion, it currently reaches more 18-34 year olds in America than any cable network, and reports revenues of $\$ 15$ billion a year (Mushroomnetworks 2020). One industry blog that identifies key advertisers on the medium as Nike, Sephora, and GoPro, claims that $62 \%$ of all businesses maintain some presence on the medium (Innovate 2020), with Apple Inc, Expedia, Geico making over one billion impressions (Statista 2020).

The state of the art strongly implicates initiating exploration (see Belanche et al. 2020a, b; Smith et al. 2012). The literature is: (a) clear that user-brand interactions on YouTube are unique, and (b) silent when it comes to identifying the cognition, affect, and behavior-related constructs native to the user-brand-YouTube interactive context to justify a purely literature-derived hypotheses testing effort. The uniqueness of the context is clear from the following; YouTube has a unique personality (Mutsikiwa and Maree 2019), and characterized by distinctive user-generated content (Miranda et al. 2021). Independent content producers on YouTube are known to shape brand perceptions differently than those active on other media (e.g., Benito et al. 2020; Lee and Watkins 2016). Similarly brand identities are communicated differently via YouTube (Huertas et al. 2017), and the ability of users to skip ads makes a difference in the way they respond to brand messages on YouTube (Belanche et al. 2020a, b). Like other media, YouTube advertising is known to aid brand recall (Belanche et al. 2020a, b), but it produces unique outcomes for luxury brands (Lee and Watkins 2016), and helps celebrity endorsers (Benito et al. 2020). While scholars have examined user generated content (e.g., Roma and Aloini 2019), and brand stories on the medium (e.g., Dessart and Pitardi, 2019), current literature does not speak to the research questions driving our study; i.e., to YouTube users' brand-related attributions and the processes that produce them.

There is also a strong case for exploring YouTube users' cognitive and emotional attributions toward brands in the branding literature. For instance, brands are conceptualized as emotional things (Thomson et al. 2005). Current views hold that brands: (a) are gestalts, and reflect an amalgamation of tangible and intangible value (Murphy 1992), (b) trigger emotions, convey meaning, and help consumers make sense of the world around them (Fournier and Alvarez 2019; Holt 2002; Keller 2003; Keller and Lehmann 2006), (c) are symbolic versus the entirely tangible and the literal (e.g., Aaker 1996; Aaker et al. 2001). This attention to emotions and symbolic meanings of brands is apparent in research devoted to social media usage as well (e.g., Gielens and Steenkamp 2019; Hughes et al. 2019; Tellis et al. 2019; Torelli and Ahluwalia 2012). Initial exploration of what brands mean, and how and why these meanings emerge as a result of user-YouTube interaction, is clearly implicated and aligned with key contributions in branding research (see Aaker 1996; Keller and Lehman 2006).

\section{Research method}

\section{Generation of grounded theory}

We conducted five focus groups in the period of October-November 2019 among self-described frequent users of YouTube (over one hour a day) from a sample of Generation Z-age (20-22 years) students enrolled in multiple sections of undergraduate marketing and MBA courses offered at a B-School in northeastern US. Based on transcripts of five focus groups, we derived a grounded conceptual framework, measurement scales and hypotheses (42 participants). In each class, at any one time, while eight to nine volunteers participated in the focus group, the rest of the students were asked to observe and draw inferences. In each class, all volunteers had the opportunity to participate in a focus group, and observe one or more groups for the purpose of inference drawing. Each focus group began with the following direction from one of the co-authors:

The purpose of this focus group is to learn about how and why you use YouTube, how and why you inter- 
act with brands on this medium in the ways you do, and what do you think and feel about the brands you encounter on this medium.

After focus groups were concluded, all students were asked to draw inferences based on what they saw and heard, and frame their thinking around: "when was said in the focus group, I inferred __.." After students had worked in teams, the instructor led discussions on key inferences and developed frameworks on the whiteboard based on participants' responses (that were photographed at the end of class). The transcripts of focus groups, the student-identified 'nuggets' or statements that spoke to motivations that drive YouTube usage, the nature of user-YouTube interaction, and the resulting user-brand interaction in the medium, and the photographs of the whiteboard were shared among co-authors who separately conducted qualitative data analysis.

\section{First-stage data analysis}

The process of data analysis sought inspiration from Cronbach and Meehle (1955), and closely followed guidelines of Miles et al. (2014). Briefly, each co-author examined the transcripts, photographs of frameworks constructed on white boards in class (encapsulating class discussions), and instructor notes made after the focus groups were concluded. Based on this material, each co-author separately identified key themes associated with the key questions asked; i.e., (a) why participants used YouTube, (b) what did participants do on the medium, (c) how and why participants interacted with brands on the medium in ways they did. Each theme was supported by statements from participants. For instance, all statements related to 'why I use YouTube' were initially generated. Based on this list of statements, a descriptive term was used to describe the most focal latent construct. Finally, the statements that captured the breadth of concerns were translated into Likert scales to aid measurement. Once the list of statements and potential latent constructs were identified, the co-authors met to check on inter-coder reliability. Despite differences in labels, there was overwhelming agreement among four key constructs we identified, that served as the basic ontology of the grounded theory we propose; i.e., social dread as an antecedent of YouTube usage, comfort finding and rabbit holing as the principle, first-order outcomes of YouTube usage, and the attribution of brands as a personal narrative as a second-order consequence (for more on ontology as the building blocks of theories, see Laudan (1977)).

\section{Grounded findings, an ontology, scales and hypotheses}

Figure 1 illustrates the conceptual framework we inductively derived from participants' voices; it makes explicit our data derived notions of convergence (i.e., relationships we hypothesize as significant, see $\mathrm{H} 1$ through H5), and discriminance (i.e., the constructs are presented as conceptually distinct; the absence of arrows between shown boxes indicate our learning of unconnected constructs). Similarly, Table 1 shows the constitutive and operational definitions of the constructs (Likert scale items). The constructs are the data-derived ontology, the conceptual building blocks of the theoretical notions of user-brand interactions on YouTube that we present in this paper (see Laudan 1977).

This discussion is devoted to five key findings. First, while our questions asked 'tell us about how and why you interact with brands,' we found no evidence of a two-way interaction. YouTube users consume brand-related information; they do not speak to brands on the medium in any significant way. We find no significant evidence of a twoway communication occurring to enable framing of testable hypotheses. Second, participants describe social dread as a key driver of YouTube usage. They feel dreadful; it is a term used by participants across focus groups. While dread connotes extreme fear and apprehension, participants describe social dread in reference to the distance between where they are, and where they would like to be, in their social relationships with others. As the definition and scales in Table 1 show, social dread is a negative mood state; it relates to social stress, fear of negative responses and judgment of others, and the inability to relate or connect with others.
Fig. 1 A model of brand as personal narrative (February 2020, pre-Covid, $n=343$ ). Fit parameters: $\mathrm{NFI}=.931$, $\mathrm{NNFI}=.97, \mathrm{CFI}=.974$, $\mathrm{IFI}=.974, \mathrm{RMSEA}=.041$

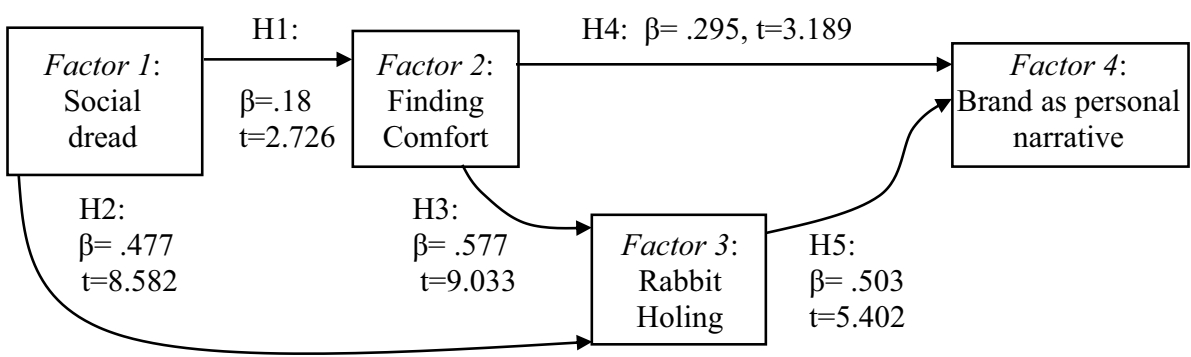

Fit parameters: $\mathrm{NFI}=.931, \mathrm{NNFI}=.97, \mathrm{CFI}=.974, \mathrm{IFI}=.974, \mathrm{RMSEA}=.041$ 
Table 1 Constructs, scales, measurement model and standardized solutions

\begin{tabular}{|c|c|c|c|c|}
\hline \multicolumn{2}{|c|}{$\begin{array}{l}\text { Measurement model ( } \mathrm{t} \\
\text { statistic) }\end{array}$} & \multirow[t]{2}{*}{ Latent constructs, definitions and measured variables } & \multicolumn{2}{|c|}{$\begin{array}{l}\text { Standardized solution ( } \mathrm{R} \\
\text { square) }\end{array}$} \\
\hline $\begin{array}{l}\text { Pre-Covid } \\
\text { February }\end{array}$ & $\begin{array}{l}\text { Vaccine- } \\
\text { present May }\end{array}$ & & $\begin{array}{l}\text { Pre-Covid } \\
\text { February }\end{array}$ & $\begin{array}{l}\text { Vaccine- } \\
\text { present May }\end{array}$ \\
\hline
\end{tabular}

Latent construct: Social dread

Constitutive definition: The extent to which a YouTube user feels anxiety, stress, fear, awkwardness about relating to others

$\begin{array}{lllll}1 & 1 & \text { D1 I am often stressed out by other people } & 0.769(.59) & .775(.60) \\ 1.182(20.11) & 1(21.44) & \text { D2 I am often afraid that people will respond negatively to what I have to say } & 0.841(.70) & .771(.59) \\ 1.131(18.29) & .973(18.56) & \text { D3 I often feel awkward in social situations } & 0.825(.6) & .778(.60) \\ 1.175(18.13) & 1.082(19.95) & \text { D4 I think I am often judged negatively by others no matter what I have to say } & 0.832(.69) & .804(.64) \\ 1.15(17.31) & 1.138(21.46) & \text { D5 I feel disconnected from other people } & 0.794(.63) & .837(.7) \\ 1.161(17.22) & 1.082(20.14) & \text { D6 I don't think I relate well with others in my environment } & 0.827(.68) & .809(.65)\end{array}$

Latent construct: Finding comfort

Constitutive definition: The extent to which YouTube user experiences a sense of comfort, focus, comity and relaxation while using the medium

$\begin{array}{llll}1 & \text { FC1 I feel free from everything when I am watching YouTube } & 0.732(.53) & .701(.49)\end{array}$

1.062 (11.98) 1.039 (13.73) $\quad$ FC2 When I am watching YouTube videos, I can honestly say that I feel more $\quad 0.759(.57) \quad .711(.50)$ secure

$1.012(11.4) \quad .958(11.88) \quad$ FC3 When I am watching YouTube videos, I can honestly say that I feel more $\quad 0.733(.53) \quad .682(.46)$ focused

1.122 (12.65) 1.053 (14.52) $\quad$ FC4 When I am watching YouTube videos, I can honestly say that I understand the $0.826(.68)$ world better

.898 (11.04) $\quad$.991 (12.72) $\quad$ FC5 When I am watching YouTube videos, I can honestly say that I feel better con- $\quad 0.695$ (.48) nected to the world around me

938 (10.8) 1.055 (14.29) $\quad$ FC6 When I am watching YouTube videos, I can honestly say that I feel good about $0.757(.57) \quad .754(.56)$ myself

Latent construct: Rabbit Holing

Constitutive definition: The extent to which YouTube usage serves as a compellingly endless and free-falling experience

$\begin{array}{lllllll}1 & 1 & \text { RH1 I often click through videos on YouTube aimlessly } & 0.736(.54) & .71(.50) \\ 1.03(14.74) & 1.035(15.26) & \text { RH2 How I click through the videos on YouTube suggests that I am in a free fall } & 0.749(.56) & .761(.57) \\ 1.116(16.64) & 1.129(17.06) & \text { RH3 It is very difficult for me to stop watching YouTube endlessly } & 0.805(.64) & .776(.60)\end{array}$

Latent construct: Brand as Personal Narrative (Dependent variable)

Constitutive definition: The extent to which a YouTube user's understanding and communication of self is inseparable from the brand followed on the medium

1

1.058 (22.15) 1.093 (21.9) BPN2 Thinking about and interacting with this BRAND has shaped my personality

$0.821(.67) \quad .798(.63)$

1.021 (22.36) 1.097 (24.02) BPN3 The BRAND has become part of my story I share with other people

$0.855(.73) \quad .834(.69)$

986 (19.96) 1.001 (21.11) BPN4 The BRAND has become a part of the conversation I have with others

$0.838(.70) \quad .861(.74)$

.956 (19.52) 1.053 (24.08) BPN5 I mention this brand frequently to others in order to build better connections

$0.833(.69) \quad .841(.70)$ with them

1.025 (18.38) 1.09 (19.85) BPN6 I use the BRAND name to tell interesting anecdotes to other people

$0.811(.65) \quad .837(.7)$

$0.827(.68) \quad .847(.71)$

Third, YouTube usage alleviates social dread (see $\mathrm{H} 1$ in Fig. 1). Users feel free, secure, focused, come to understand the world, and feel good about themselves (see Table 1 for definition and scale). It is more than a socioemotional reset, it is an approach to better mental health.

A comfort place ... safe zone.... I look forward to getting my tablet on and watch the videos. Stress just goes out. I wouldn't be using it as much if I wasn't just tuning out from things but feeling comfort there ... like a happy place. ... I can't wait enough . . . I feel good about myself.

Fourth, the notion that the feeling of social dread and comfort finding rapidly leads to a fall down a rabbit hole is the most recounted part of the YouTube usage experience (see $\mathrm{H} 2$ and $\mathrm{H} 3$ in Fig. 1). All focus groups use the rabbit hole analogy to explain their undirected, 'one-click-after another' 
endless occupation with YouTube as the critical gratification received (see Table 1 for definition and scale for rabbit holing, or falling down the YouTube rabbit hole). The schematic retrieved at the mention of YouTube-related free falling is: 'aimlessness,' 'free-falling,' 'inability to stop watching videos one after another' - strongly aligned with the original notion presented by Carroll (1865):

It's a rabbit hole, right there. Tripping.

I am gone. Free falling . . . tripping. Don't even wait for one video to end, I am on to the next one.

Tripping . . . yes. Mindless. One after another ... In myself case at least . . . it won't end. I love it. (It is) better than TV.

Fifth, the comfort found and the trip down the rabbit hole triggers self-construal; it is manifest in the attribution that brands are personal narratives (see $\mathrm{H} 4$ and $\mathrm{H} 5$ in Fig. 1). YouTube is fertile territory for brands; users make sense of themselves, their history and personality, and frame narratives about themselves-with the aid of brands they encounter on the medium. These 'brands as personal narratives' - while formed as a result of user-brand interaction on YouTube, are employed elsewhere to connect (see Table 1 for definition and scale). Consider the voices:

... I can tell my story but like who cares . . tune out. I know . . . I tune you out (when you tell your story). When you start I am looking to get out of there. I know. I am tripping on YouTube. Tuned in and tuned out ... (all at) the same exact time. I want to tell you I am cool ... (but) you won't care. I bring a brand into it - what I saw on YouTube because I know you are seeing it, and I know you like the brand, and then I can tell you my story, but using the brand as my thing . . .. and then you'll tell me your story (about you with the brand).

Q: What is your story you want to tell?

A: It's not a story about the brand I am telling. It's my story.

... I am orientated in my conversation. My story is me and brands. You've seen it, (name of participant) has seen it. We are now together orientated on the same thing.

... Like 'you know what I am sayin' . . ?" my story was that. After YouTube, it's like 'yeah yeah I know what you are saying, because I am that brand on YouTube ... (and) you too? . . . (are) you that brand? . . . I feel you now. You feel me? I have these brands in what I am saying to you. Then you get to tell me your story ... what is cool about you. Is why people think I am cool. 'did you see that?' I'll ask. . . I want my personality out there ... to be known, I've got to know it first. I'll have to know. That is YouTube. Who are you? Who am I? I am this way, like see these brands I hang with? That's my personality. I am telling me, maybe first, and then telling you. Express myself. Like this is where I started, then this happened, then now I am here. Like a history channel show. See how I am better now?

The exploratory data do not speak conclusively about how users employ their 'brand as narratives' in face-to-face communication with others or on other social media such as Snapchat and Instagram that they mention, nor whether such employment renders them more interesting to othersto enable generation of testable hypotheses. However, their voices provide strong evidence for further testing the following hypotheses:

H1: The greater the sense of social dread reported by YouTube user, the greater the reported extent of finding comfort as a benefit of YouTube usage.

H2: The greater the sense of social dread reported by YouTube user, the greater the reported extent of rabbit holing via YouTube usage.

H3: The greater the extent of finding comfort as a benefit of YouTube usage, the greater the reported extent of rabbit holing via YouTube usage.

H4: The greater the reported extent of finding comfort as a result of YouTube usage, the greater the extent to which users regard brands as personal narratives

H5: The greater the reported extent of rabbit holing on YouTube, the greater the extent to which users regard brands as personal narratives.

\section{Scale development and hypotheses}

The scale development process closely followed the guidelines of Churchill (1979). Briefly, the list of statements and observations associated with each of the four constructs served as the material from which the constitutive definition of the latent construct, and the operational definition in terms of indicator variables and the Likert scales were derived (see Table 1 for definitions and Likert scales). While Churchill (1979) and Hinkin (1995) advocate in favor of an independent scrutiny and triangulation of this process, resource constraints coupled with the expected challenge of demonstrating unbiased and reliable independent analysis, precluded this step. To overcome some of the problems that triangulation aims to address, the authors derived the Likert scale items based on one-to-one correspondence with statement from verbal protocols. The questionnaire we derived included: (a) a six-item scale for brand as personal narrative (BPN1-BPN6), (b) a six-item scale for social dread (D1-D6), 
(c) a six-item scale for comfort finding (FC1-FC6), and (d) a three-item scale for rabbit holing (RH1-RH3; see Table 1).

\section{Stage 1 survey}

A Qualtrix-questionnaire containing scales shown in Table 1 was circulated via Amazon's M-Turk service in later February 2020. Participation was invited from people who used YouTube at least once a day, and could name at least one brand they followed on the medium. The results discussed below relate to 343 fully completed responses we received by first week of March 2020 (see Table 2 for details of sample).

In the first stage, we conducted exploratory factor analysis on the scales we included in the questionnaire. We tested for factors based on Varimax (orthogonal) as well as Promax (oblique) rotational methods. Table 1 shows the resulting scales after the orthogonal constructs were identified. In the second step, we used EQS software to test whether any coherent structural model existed in the data prior to testing of hypotheses, whether the hypothesized measurement model shown in Fig. 1 could claim structural coherence. This process yielded factor correlations and initial estimates of the goodness of fit $(\mathrm{NNFI}=0.971, \mathrm{CFI}=0.975$, RMSEA $=0.048$ ). The factor loadings, the correlations, and

Table 2 Samples

\begin{tabular}{lll}
\hline & $\begin{array}{l}\text { February } \\
2020 \text { Pre- } \\
\text { Covid }\end{array}$ & $\begin{array}{l}\text { May 2021 } \\
\text { Covid-vaccine } \\
\text { present }\end{array}$ \\
\hline Sample size & 343 & 447 \\
1-3 h spent on YouTube per day & $57 \%$ & $54 \%$ \\
3 h or more spent on YouTube per & $43 \%$ & $46 \%$ \\
$\quad$ day & $71 \%$ & 73 \\
Male users & $27.5 \%$ & 26 \\
Female users & $1.5 \%$ & 1 \\
Other gender & $73 \%$ & $84 \%$ \\
Age 39 or under & & \\
\hline
\end{tabular}

the fit statistics suggested that latent constructs were structurally sound and conceptually distinct, and that the measurement model and standardized solutions were significant.

In the next stage, we specified paths based on the hypotheses in the SEM procedure. Figure 1 shows the parameter estimates (betas and t-statistics) yielded by the path analysis. The path parameters are significant; the model parameters indicate an excellent fit $(\mathrm{NNFI}=0.97$, $\mathrm{CFI}=0.974, \mathrm{IFI}=0.974, \mathrm{RMSEA}=0.041)$. Table 1 shows the estimates based on the measurement model (see leftmost column 1) and the standardized solutions, the loadings obtained from confirmatory factor analysis ( $\mathrm{R}$ squares in parentheses). The composite reliabilities and discriminant validity of latent constructs were assessed based on these factor loadings (based on Fornell and Larcker 1981).

The factor loadings shown in Table 1 served as a basis for testing composite reliability and convergent and discriminant validity of latent constructs. Table 2 shows the results of this analysis. Briefly, the composite reliability of the latent constructs ranges from 0.81 to 0.95 , i.e., well in excess of the 0.7 (e.g., Hair et al. 2006). The average variance extracted (AVE) constructs exceeds 0.5 for supporting inference of convergent validity. Discriminant validity is inferred from the following. First, the highest correlations among latent constructs is 0.672 (between rabbit holing and brand as narrative). Correlations of 0.8 or higher can interfere with inference of discriminant validity; it is hard to claim that the two constructs are conceptually dissimilar if correlations are high (e.g., Yanamandram and White 2010). Second, the calculated AVEs are higher than all possible squared correlations between latent constructs (see Table 3), suggesting that the variance in the latent construct explained by the indicator variables exceeds that which can be explained by other constructs. The AVEs also exceed the maximum shared variance (MSV), which in the data refers to 0.452 (square of the correlations coefficient between rabbit holing and brand as narrative). Similarly, the AVE exceeds average shared variance (ASV), calculated as the average of squared correlations between all pairs of latent constructs (ASV $=0.235)$.
Table 3 Reliability and construct validity statistics $(n=343$, February 2020, PreCovid)

\begin{tabular}{|c|c|c|c|c|c|c|c|}
\hline & \multirow[t]{2}{*}{ Factor variance } & \multirow{2}{*}{$\begin{array}{l}\text { Cron- } \\
\text { bach's } \\
\text { alpha }\end{array}$} & \multirow{2}{*}{$\begin{array}{l}\text { Composite } \\
\text { reliability }\end{array}$} & \multicolumn{4}{|c|}{$A V E s$ and Correlations ${ }^{2}$} \\
\hline & & & & F1 & $\mathrm{F} 2$ & F3 & F4 \\
\hline F1: Social dread & .878 & .922 & .95 & .75 & .175 & .559 & .424 \\
\hline F2: Finding comfort & .587 & .884 & .92 & .031 & .63 & .659 & .635 \\
\hline F3: Rabbit holing & .829 & .812 & .81 & .312 & .434 & .58 & .672 \\
\hline F4: Brand as personal narrative & 1.027 & .93 & .86 & .18 & .403 & .452 & .69 \\
\hline
\end{tabular}

${ }^{1}$ Cronbach's alpha, as an indicator of scale reliability, calculated via SPSS based on indicator variables of the latentconstruct

${ }^{2}$ The bold italics indicate the calculated AVEs for each latent construct. Numbers above the diagonal are factor correlations, those below the diagonal are squared correlations. All AVEs equal or exceed squared correlations indicated below the diagonal 


\section{Stage 2 sample, survey, and hypotheses validation}

By the time the survey data were analyzed, the Covidpandemic had triggered staggering changes in the psychosocial and socioeconomic landscape of YouTube users (among others). These external events produced an opportunity to test the robustness of the scales and model. Hence, we conducted a nationwide study when Covidvaccine supply in the US began to exceed the number of adults interested in taking the vaccine (late April 2021). The same Qualtrics survey was sent to a nationwide sample of YouTube users in early May 2021 (participants in the first survey, identified by their MTurk generated identifiers, were not re-contacted). The data collection was completed in the first week of May 2021.

Figure 2 shows the path parameters that emerged from SEM procedure using EQS software (see Table 1 for parameters of the measurement model and the standardized solutions). The hypothesized paths are significant, and present evidence in support of all hypotheses. The details of the second-stage sample are included in Table 2. Table 4 highlights the key statistics from which support for reliability and construct validity of scales was discerned. Briefly, Cronbach's alpha exceed 0.7, composite reliability ranges from 0.79 to 0.94 and provide evidence to support an inference of scale reliability. AVEs exceed 0.5 (suggesting convergent validity), and exceed the squared correlations among factors (see Table 4).

\section{Findings}

The significant parameter estimates of path analysis, and the fit parameters of the hypothesized models shown in Figs. 1 and 2 suggest that the qualitative study derived latent constructs, indicator variables, the conceptual models and hypothesized relationships are robust; the period of 15 months (February 2020 to May 2021), the disruptive pandemic, did not significantly alter the support for hypothesized relationship. Some differences are worthy of note. First, there is an uptick in the proportion of sample that reports YouTube usage of $3 \mathrm{~h}$ or more per day (from 43 to $46 \%$ ). Similarly, there is an uptick in the proportion of YouTubers who are age 39 or under (from 74 to $84 \%$ ). A test for significance of difference was precluded because data were gathered not as a discrete number on a ratio scale, but on an ordinal scale. Third, all correlations between factors, except the one finding comfort and rabbit holing (F2 and F3) increased in magnitude during the 15-month period. This suggests some weakening of construct validity without rendering hypothesized relationships insignificant or invalid. Whether these correlations change as the pandemic recedes in effect and in the memory of YouTube users, deserves examination at future points in time. Moreover, why the
Fig. 2 A model of brand as personal narrative (Vaccine-present May 2021, $n=447$ )

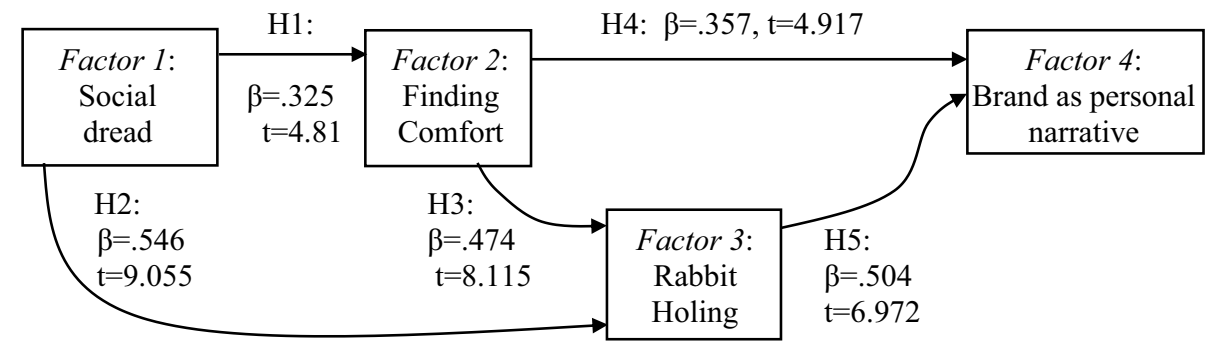

Fit parameters: $\mathrm{NFI}=.925, \mathrm{NNFI}=.955, \mathrm{CFI}=.961, \mathrm{IFI}=.961, \mathrm{RMSEA}=.048$
Table 4 Reliability and construct validity statistics $(n=448$, May 2021, Vaccinepresent)

\begin{tabular}{|c|c|c|c|c|c|c|c|}
\hline & \multirow[t]{2}{*}{ Factor variance } & \multirow{2}{*}{$\begin{array}{l}\text { Cron- } \\
\text { bach's } \\
\text { alpha }^{1}\end{array}$} & \multirow{2}{*}{$\begin{array}{l}\text { Composite } \\
\text { reliability }\end{array}$} & \multicolumn{4}{|c|}{$\boldsymbol{A V E} \boldsymbol{s}$ and Correlations ${ }^{2}$} \\
\hline & & & & $\mathrm{F} 1$ & $\mathrm{~F} 2$ & F3 & F4 \\
\hline F1: Social dread & .958 & .912 & .94 & .71 & .382 & .708 & .448 \\
\hline F2: Finding comfort & .489 & .855 & .9 & .108 & .54 & .653 & .684 \\
\hline F3: Rabbit holing & .732 & .792 & .79 & .501 & .426 & .56 & .748 \\
\hline F4: Brand as personal narrative & 1.022 & .933 & .86 & .201 & .468 & .56 & .7 \\
\hline
\end{tabular}

${ }^{1}$ Cronbach's alpha calculated via SPSS based on indicator variables of the latent construct

${ }^{2}$ The bold italics indicate the calculated AVEs for each latent construct. Numbers above the diagonal are factor correlations, those below the diagonal are squared correlations. All AVEs equal or exceed squared correlations indicated below the diagonal 
correlations increased in magnitude among some and not all factors are not explained by current data, future investigation of these differences seem necessary. Finally, in either sample, we found no significant differences in the means on any of the measured variables based on gender.

\section{Implications for theory and practice}

\section{Findings resonant with literature}

Our findings about social dread as a negative mood state that drives social media usage resonates with current notions. For instance, much is written about the fear of missing out (Tandon et al. 2021), about fear of being ignored (Sashittal and Jassawalla 2019a), and the fear of inauthenticity as drivers of social media usage (Sashittal and Jassawalla 2019b). The notion that social dread will lead people to avoid cognitively demanding tasks (e.g., Gonzalez-Garcia et al. 2021), and lead to rabbit holing - as a natural response to alleviating discomfort and prolonging feelings of comfort, has received the ponder of philosophers (Kierkegaard 1957), empirical analysis by psychologists (Cook and Newins 2021; Harris 2012), marketing scholars (e.g., Gwinner et al. 1998; Hennig-Thurau et al. 2000), and social economists (Scitovsky 1992). Similarly, the notion that social dread will lead to comfort finding is predicted in the positive psychology literature (e.g., Daniels 2000). Finally, the study produces some evidence that speaks to key developments in positive psychology; scholars suggest that self-awareness disrupts optimal experiences and that passion for an activity is subdued as a result of gaining self-awareness (Csikszentmihalyi 1990). We learn, that rabbit holing as an optimal, flow-like experience where YouTube users experience a free fall in which they lose track of time produces a sense-making, an awareness of self, and a personal narrative.

\section{Brand as personal narrative}

Current branding literature overwhelmingly suggests that brand narratives are managed and curated by brand sponsors (Alvarado-Karste and Guzmanm 2020; Bonnin and Alfonso 2019; Ganassali and Matysiewicz 2021). The purpose of the narration varies; brands make statements about themselves, take a stand about what they value (Milfeld and Flint 2021), create new value (Ganassali and Matysiewicz 2021), shape consumers' cognitive schemas (Bowden and Mirzaei 2021), and provide a basis for connections and a sense of attachment with the brand (Eng and Cheryl 2020). Firms curate and manage brand meanings and images (see Chang et al. 2019 for exhaustive review) and brand biographies (Thanh-Thao and Grohman 2020), similarly people manage and curate the messages about themselves as brands (Confente and Kucharska 2021; Kucharska et al. 2020; Smith and Fischer 2021). Recent evidence indicates how brand sponsors produce narratives about authenticity (Moulard et al. 2021), green credentials and trust (Huang and Guo, 2021), and connections between celebrities who are brands and people (Eng and Cheryl 2020). On YouTube, brand sponsors tell their stories via audiovisual engagement (see Huertas et al. 2017; Verhellen et al. 2013). The notion of brands as personal narratives-explicated by our study, are distinct from current notions of brand narratives (see Eun-Ho et al. 2021; Pace 2008; see Schembri et al. 2010).

The purpose served by brands as personal narratives, and implications they hold for future theory and practice, deserve brief iteration. The attribution-brands as personal narratives-serves two inextricable purposes for YouTube users. First, this attribution serves a selfconstrual related function; it shapes a soliloquy about the brand and its integration into the user's personal history and into her/his personality (see items BPN1 and BPN2 in Table 1). Second, the attribution serves a social function; it allows users to frame conversations with others about the self-enriched by brands as part of the personal narrative-to make one more interesting to others (see items BPN4-BPN6 in Table 1). How this 'brand as personal narrative' is manifest in face-to-face interactions with others, or in engaging others on other social media such as Instagram and Snapchat as mentioned by some participants in the first-stage focus groups-is not revealed in the data in ways that produce a testable hypothesis; it deserves additional empirical scrutiny. However, the dual function of a narrative for self, and for others, and their inseparability is indicated repeatedly; from multiple iterations of factor analysis (EFAs using Varimax, orthogonal rotation, and Promax, oblique rotations, then CFAs during the process of fitting an SEM to test the hypothesized model). Moreover, the unidimensionality is robust across two separate surveys taken over a year apart during which the Covid-19 pandemic triggered widespread changes in consumers' and YouTube users social-psychology.

The theoretical and practical implications speak to the emerging power of YouTube users and brand sponsors in an interactive context. On YouTube: (a) brand sponsors do not fully control brand narratives-users shape the narrative for their purposes of self-construal and for connecting with others, (b) users do not derive a personal narrative independent of brands. Brands are powerful; they feature into self-construal and in narratives designed to connect with others. YouTube users are powerful; their personal narrative supplants the brand narrative independently produced by brand sponsors. 


\section{Social dread and social anxiety}

The principal argument we derive from the findings, that is new to the literature, is that a negative mood state of social dread is alleviated by social media usage; that the social dread triggers rabbit holing and a self-construal that eventually produces a personal narrative that features brands (and aligns with recent evidence about motivators of social media usage; see Sashittal and Jassawalla, 2019a, 2020). YouTube users are not succumbing to social dread to further dysfunctional outcomes; they are seeking solutions that help them better understand themselves and connect with others.

Questions about the distinction between social dread and social anxiety are anticipated; prima facie they seem identical. The research on social anxiety is inordinately well developed; a wide array of constituencies-ranging from psychologists, counsellors, and marketers of psychotropic therapies-are wedded to its centrality in understanding the human condition (see Alkis et al. (2017), Cook and Newins (2021), Goodwin et al. (2020), and Juyoen et al. (2020) for notable contributions and measurement scales for anxiety). One option, given our findings, is to view YouTube usage entirely from the lens of social anxiety. Assessing whether existing social anxiety scales would measure the same social dread, and relate to other factors as we hypothesize social dread does-is left to future research. Our purpose here is to present evidence that point to important differences; i.e., an attempt that is wholly different from the proposition that the notion of social dread is entirely new, or entirely disconnected from notions of social anxiety.

Conceptual distinction is highlighted when the dataderived scale is compared and contrasted with extant theory. Social anxiety is indicated by fear that one's performance is inadequate and will be judged harshly by others; it relates to the anticipation of more anxiety-provoking situations and results in avoidance, panic, disconnection, and other dysfunctional emotional and behavioral states (Bogels et al. 2010). Moreover, social anxiety is a disorder (Stein and Stein 2008), a disabling psychological condition (Zamorski and Ward 2000), known to impair cognitive and sociological functions (Rose and Tadi 2021) and an unnatural pathology deserving of intervention and therapy (Rodebaugh et al. 2004; Hickinbottom-Brawn 2013). Social dread is a sub-clinical feeling of being different, disconnected, awkward and concerned about not relating with others. It raises the question: 'is social dread just diluted, low-level social anxiety?'.

This question too is addressed by comparing findings and the literature. Social anxiety is anteceded by feelings of low self-efficacy (Gelbrich and Sattler 2014) and fear that others will offer negative evaluations (Alkis et al. 2017). These notions are intrinsic to the data-derived notion of social dread, and do not emerge as antecedents (see scale shown in Table 1). Kierkegaard (1957), referred to dread in the same context of endless possibilities, a notion akin to a rabbit holing experience; i.e., he notes that endless possibilities can produce dread; not as we find that social dread is alleviated with endless possibilities presented by rabbit holing on YouTube. Social anxiety produces consequences of lower peer acceptance, depression and dissociative behaviors (Hebert et al. 2013; Parade et al. 2010). Social dread triggers solution seeking on YouTube and a fall down the rabbit hole, eventually to self-construal and the attribution of brands as personal narratives (see Gabel and McAuley 2020). Social anxiety literature makes little mention of salubrious outcomes such as solution seeking; rather it points largely to its treatment as a pathology for which few even seek help from others (see Griffiths et al. (2017); Rodebaugh et al. (2004) for exhaustive review of treatments and interventions). If YouTube users were feeling social anxiety in the ways it is currently conceptualized, it would follow that usage would trigger further anxiety (based on Page et al., 2018; Twenge 2013), to the avoidance of its usage (based on Bogels et al., 2010), or produce evidence of dysfunctional or addictive usage (based on Cao et al. 2020). We find almost entirely opposite consequences of social dread in the user-YouTube-brand interactions. Social dread of YouTube users does not appear to devolve into dysfunctional socioemotional or behavioral outcomes. While current thinking about user-social media interaction points to negative, unhealthy, often pathological anxiety and addiction (see Reyes, et al. 2021; Watson et al. 2020), our findings align with evidence of its salubrious effects (see Lu et al. 2020).

The discussion of dread as not an entirely dysfunctional emotion is found in literature that has remained outside of current thinking about branding and social anxiety. For instance, the term dread was used by Kierkegaard (1957) to signify what one feels when one anticipates the future and feels overwhelmed. As Kierkegaard (1957) and modern psychoanalysts (e.g., Bion 1962; Stone 2017) indicate, dread-not anxiety—antecedes the discovery of self-a notion to which our findings lend support. We find a link to which Stone (2017) alludes; social dread eventually leads to self-construal and narratives in which brands are used to foster better connections with others. In sum, therefore, we find sufficient distinctions between data-derived notions of social dread and literature's discussion of social anxiety to preclude an inference they are identical constructs.

\section{Comfort finding}

The data produce insights into a salubrious context of branding; i.e., social dread-relieving, comfort finding context of YouTube usage which produces a self-construal, and the attribution of brands as personal narratives. YouTube users make sense of themselves and figure out a way to make 
themselves more interesting to others in a space of comfort finding, free falling, and brands. This data-derived notion of healthy YouTube usage is new to the literature otherwise devoted to listing negative psychosocial outcomes of social media usage (see Jang et al. 2008; Karahanna, et al. 2015 for notable exceptions). For instance, much is known about negative effects of social media usage including anxiety and fatigue (Malik et al., 2020), narcissism (Reyes et al., 2021), celebrity worship (Zslila, et al. 2018) and cyberstalking (Begotti, et al., 2020). While the deleterious behaviors associated with YouTube, and addiction to YouTube deserve investigation, our study points to triggering of positive feelings; i.e., a sense of freedom, security, gaining focus, understanding and connectedness with the world, and a 'feeling good about myself.' YouTube usage emerges as therapeutic; it alleviates social dread; i.e., all social media engagement may not align with negative psychology, or reflect pathologies that deserve treatment and intervention. The salubrious outcomes of social media usage deserve additional academic scrutiny. If brand sponsors were concerned about framing a narrative around this is how this brand is worthy, the findings suggest framing around this is how you, the YouTube user, can make yourself more worthy, interesting to others by integrating our brand into your personal narrative.

\section{Rabbit holing and self-construal}

Branding literature is relatively less informed by the development in thinking about the rabbit holing and comfort finding associated with gaming (e.g., Chess and Booth 2014; Mims 2007), or with personal accounts of rabbit holing behavior (Allbons, 2012). Current discussions of rabbit holing are disconnected from thinking about branding (e.g., Hoover and Richardson (2008); see Bock et al., (2020) for notable exception). In particular, how rabbit holing experiences can shape, and ultimately contribute to healthier user-brand relationships deserves additional research.

Social dread alleviation, and free falling in a rabbit hole, our findings suggest, engender a self-construal, cognitive processes that integrate the brand with the sense of self (history and personality), and with the attribution that brands are personal narratives. Branding research and practice is likely better served if this inseparability is recognized, and the role of free-falls in shaping the emotional attributions to brands are acknowledged. In this regard, self-construal has received considerable attention from psychologists (Ashfort and Mael 1989; DeRue and Ashford 2010). It is about making sense of oneself in relation to others (Cross et al. 2000), in order to figure out how to behave with others (e.g., Gino and Galinsky 2012). It is about people making sense of themselves as individuals (Johnson et al. 2006), as people in relationships with others (Brewer and Chen 2007), and as part of a collective (Yang et al. 2012). Branding literature too has examined how self-construal is an influencer of brand evaluation (Swaminathan et al. 2007). Moreover, self-construal resulting from social media usage is known to enhance perceptions of one's social value (Jiao et al. 2017), shape brand loyalty (Eun-Ho et al. 2021), and increase indulgent consumption among men (Chang et al. 2021). Despite this interest in the self-construal construct, this is the first study to present evidence of brands as self-construal produced personal narratives.

Notions of user-defined narratives that feature brands, the role of rabbit holing and comfort finding in this process, together point to a rapidly altering reality in which brand sponsors and managers are losing power to independently curate messages, images and narratives for their brands to users of YouTube. Similar findings have emerged from a study of Instagram users who rely on the tribal leaders they follow - and not brand managers - to curate brands for their personal consumption, and award select brands as artifacts of the Instagram tribes in which they are members (see Sashittal and Jassawalla 2020). In the Instagram context as well, the power to manage messaging and curating brand messages is moving away from managers and brand sponsors and toward Instagram celebrities and tribal leaders. Our findings too suggest the declining power of brand sponsors, and brand images; a brand is only as good as the extent to which it serves YouTube users' need to create a personal narrative that helps them connect with others.

\section{Future research and conclusion}

Where the 'brands as personal narratives' are employed by YouTube users (i.e., during interpersonal communication and/or on other social media) deserve additional exploration; whether they do indeed produce the intended connections with others also deserves future testing. Our findings do not speak to these issues. Moreover, the emerging reality of user-social media-brands, and user-YouTube-brands is altering the landscape in which branding is defined and understood by theoreticians, and the way brands are managed by firms. New theories are needed to understand, predict, and explain these emerging realities in which users-social media-brands interact in one inseparable context. The user-brand interactions on social media are placing users in the driver's seat; they are framing the reality of brands as much, if not more, than brand sponsors. While much of the current attention is to unhealthy, even pathological issues of user-social media interactions, the salubrious, therapeutic outcomes of social media usage, and the emergence of new ways of defining brands by users-are unignorable. No single study can capture the entire complexity of user-YouTube-brand interactions, our data-derived notions of social dread, comfort finding, 
rabbit holing, and brands as personal narratives are new to the literature, hold new theoretical and practical implications, and robust across dramatic shifts caused by the Covid-19 pandemic.

Finally, the SEM procedure was used to test hypotheses simultaneously, inferences of causality should proceed with caution (e.g., Fornell and Larcker 1981). Moreover, given that we asked the sample to also rate the dependent variable of the study (i.e., brand as personal narrative), the estimates are subject to inflation because of common methods bias reports (Podsakoff et al. 2003). Hence, we assessed construct reliability and discriminant validity of scales (based on Conway and Lance's (2010) guidelines).

\section{References}

Aaker, David A. 1996. Building Strong Brands. New York, NY: The Free Press.

Aaker, J., V. Benet-Martinez, and J. Garolera. 2001. Consumption symbols as carriers of culture: A study of Japanese and Spanish brand personality constructs. Journal of Personality and Social Psychology 81 (3): 492-508.

Aggarwal, P., and A.L. McGill. 2007. Is that car smiling at me? Schema congruity as a basis for evaluating anthropomorphized products. Journal of Consumer Research 34 (4): 468-479.

Alkis, Y., Z. Kadirhan, and M. Sat. 2017. Development and validation of social anxiety scale for social media users. Computers in Human Behavior 72: 296-303.

Allbon, C. 2012. Down the rabbit hole-curiouser and curiouser: Using autoethnography as a mode of writing to re-call, re-tell and re-veal bodily embodiment as self-reflexive inquiry. Journal of Organizational Ethnography 1 (1): 62-71.

Alvarado-Karste, D., and F. Guzman. 2020. The effect of brand identity-cognitive style fit and social influence on consumerbased brand equity. Journal of Product \& Brand Management 29 (7): 971-984.

Ashfort, A.E., and F. Mael. 1989. Social identity theory and the organization. Academy of Management Review 14: 20-39.

Batra, R., A. Ahuvia, and R.P. Bagozzi. 2012. Brand love. Journal of Marketing 76 (2): 1-16.

Begotti, T., M. Bollo, and D.A. Maran. 2020. Coping strategies and anxiety and depressive symptoms in young adult victims of cyberstalking: A questionnaire survey in an Italian sample. Future Internet 12 (8): 136-149.

Belanche, D., L.V. Casaló, C. Orús C, and A. Pérez-Rueda. 2020a. Developing a learning network on YouTube: Analysis of student satisfaction with a learner-generated content activity. In Educational Networking, Lecture Notes in Social Networks, ed. Pena-Ayala, A. Springer: Cham. https://doi.org/10.1007/ 978-3-030-29973-6_6.

Belanche, D., C. Flavian, and A. Perez-Rueda. 2020b. Brand recall of skippable vs non-skippable ads in YouTube. Online Information Review 44 (3): 545-562.

Benito, S.M., A.E. Illera, and E.O. Fernandez. 2020. YouTube celebrity endorsement: Audience evaluation of source attributes and response to sponsored content. A case study of influencer Verdeliss. Communication and Society 33 (3): 149-166.

Betan, E., K.A. Heim, C.Z. Conklin, and D. Westen. 2005. Countertransference phenomena and personality pathology in clinical practice: An empirical investigation. The American Journal of Psychiatry. https://doi.org/10.1176/appi.ajp.162.5.890.

Bion, W.R. 1962. Learning from Experience. London: Heinemann.

Bock, D.E., J. Wolter, and O.C. Ferrell. 2020. Artificial intelligence: Disrupting what we know about services. The Journal of Services Marketing 34 (3): 317-334.

Bogels, S., L. Alden, D.C. Beidel, L.A. Clark, D.S. Pine, M.B. Stein, and M. Voncken. 2010. Social anxiety disorder: Questions and answers for the DSM-V. Depression and Anxiety 27 (2): $168-189$

Bonnin, G., and M.R. Alfonso. 2019. The narrative strategies of B2B technology brands. Journal of Business \& Industrial Marketing 34 (7): 1448-1458.

Bowden, J., and A. Mirzaei. 2021. Consumer engagement within retail communication channels: An examination of online brand communities and digital content marketing initiatives. European Journal of Marketing 55 (5): 1411-1439.

Brewer, M.B., and Y. Chen. 2007. Where (Who) are collectives in collectivism? Toward conceptual clarification of individualism and collectivism. Psychological Review 114 (1): 133-151.

Cao, X., M. Gong, L. You, and B. Dai. 2020. Exploring the mechanism of social media addiction: An empirical study from WeChat users. Internet Research 30 (4): 1305-1328.

Carroll, L. 1865. Alice's Adventures in Wonderland. New York, NY: MacMillan.

Chang, C.T., D. Tok, X. Chu, Y.K. Lee, and S. Wang. 2021. Does "hot" lead to "not so hot?" European Journal of Marketing 55 (5): 1313-1337.

Chang, Y., Y. Li, Y. Jun, and V. Kumar. 2019. Getting more likes: The impact of narrative person and brand image on customerbrand interactions. Journal of the Academy of Marketing Science 47 (2): 1027-1045.

Chess, S., and P. Booth. 2014. Lessons down a rabbit hole: Alternate reality gaming in the classroom. New Media and Society 16 (6): 1002-1017.

Chiang, H.-H., A. Chang, T.S. Han, and D. McConville. 2013. Corporate branding, brand psychological ownership and brand citizenship behaviour: Multilevel analysis and managerial implications. Journal of General Management 39 (1): 55-80.

Churchill, G.A. 1979. A paradigm for developing better measures of marketing constructs. Journal of Marketing Research 16 (1): 64-73.

Confente, I., and W. Kucharska. 2021. Company versus consumer performance: Does brand community identification foster brand loyalty and the consumer's personal brand? Journal of Brand Management 28: 8-31.

Conway, J.L., and C.E. Lance. 2010. What reviewers should expect from authors regarding common methods bias in organizational research. Journal of Business Psychology 23 (3): 325-334.

Cook, M.A., and A.R. Newins. 2021. Social anxiety and dissociation: The moderating role of emotion regulation. Motivation and Emotion 45 (3): 345-353.

Cronbach, L.J., and P.E. Meehl. 1955. Construct validity in psychological tests. Psychological Bulletin 52 (4): 281-302.

Cross, S.E., P.L. Bacon, and M.L. Morris. 2000. The relationalinterdependent self-construal and relationships. Journal of Personality and Social Psychology 78 (4): 791-808.

Csikszentmihalyi, M. 1990. Flow: The psychology of optimal experience. New York, NY: Harper \& Row.

Daniels, K. 2000. Measures of five aspects of affective well-being at Work. Human Relations 53 (2): 275-294.

Dessart, L., and V. Pitardi. 2019. How stories generate consumer engagement: An exploratory study. Journal of Business Research 104: 183-195. 
DeRue, D.S., and S.J. Ashford. 2010. Who will lead and who will follow? A social process of leadership identity construction in organizations. Academy of Management Review 35: 627-647.

Eng, B., and B.J. Cheryl. 2020. Consumers and their celebrity brands: How personal narratives set the stage for attachment. The Journal of Product and Brand Management 29 (6): 831-847.

Eun-Ho, K., D. Yoo, and D. Sun-Jae. 2021. Self-construal on brand fan pages: The mediating effect of para-social interaction and consumer engagement on brand loyalty. Journal of Brand Management 28 (3): 254-271.

Fornell, C., and D.F. Larcker. 1981. Structural equation models with unobservable variables and measurement error: Algebra and statistics. Journal of Marketing Research 18 (3): 382-388.

Fournier, S., and C. Alvarez. 2019. How brands acquire cultural meaning. Journal of Consumer Psychology 29 (3): 519-534.

Funk, M. 2020. YouTube $2^{\text {nd }}$ biggest search engine- The myth that just won't die. Tubics. https://www.tubics.com/blog/youtube2nd-biggest-search-engine/.

Gabel, M.S., and T. McAuley. 2020. React to act: Negative mood, response inhibition, and the moderating role of emotional reactivity. Motivation and Emotion 44 (6): 862-869.

Ganassali, S., and J. Matysiewicz. 2021. Echoing the golden legends: Storytelling archetypes and their impact on brand perceived value. Journal of Marketing Management 37 (5-6): 437-463.

Gelbrich, K., and B. Sattler. 2014. Anxiety, crowding, and time pressure in public self-service technology acceptance. Journal of Services Marketing 28 (1): 82-94.

Gerbing, D., and J. Anderson. 1988. An updated paradigm for scale development incorporating unidimensionality and its assessment. Journal of Marketing Research 25: 186-192.

Gielens, K., and J.E.M. Steenkamp. 2019. Branding in the Era of digital (Dis)intermediation". International Journal of Research in Marketing 36 (3): 367-384.

Gino, F., and A.D. Galinsky. 2012. Vicarious dishonesty: When psychological closeness creates distance from one's moral compass. Organizational Behavior and Human Decision Processes 119: $15-26$.

Gonzalez-Garcia, C., B. Garcia-Carrion, R. Lopez-Benitez, A. Sobrado, A. Acosta, and M. Ruz. 2021. Induced affective states do not modulate effort avoidance. Psychological Research Psychologische Forschung 85 (3): 1016-1028.

Goodwin, R.D., A.H. Weinberger, J.H. Kim, M. Wu, and S. Galea. 2020. Trends in anxiety among adults in the United States, 2008-2018: Rapid increases among young adults. Journal of Psychiatry Research 130: 441-446.

Griffiths, K.M., J. Walker, and P.J. Batterham. 2017. Help seeking for social anxiety: A pilot randomized controlled trial. Digital Health. https://doi.org/10.1177/2055207617712047.

Griffiths, M.A. 2018. Brand vulgarity. The Journal of Product and Brand Management 27 (4): 404-414.

Gwinner, K.P., D.D. Gremler, and M.J. Bitner. 1998. Relational benefits in services industries: The customer's perspective. Journal of the Academy of Marketing Science 26 (2): 101-114.

Hair, J.F., W.C. Black, B.J. Babin, R. Anderson, and R.L. Tatham. 2006. Multivariate Data Analysis (6th ed.). Upper Saddle River, NJ: Pearson University Press.

Harris, C.R. 2012. Feelings of dread and intertemporal choice. Journal of Behavioral Decision Making 25 (1): 13-28.

Hebert, K.R., J. Fales, D.W. Nangle, A.A. Papadakis, and R.L. Grover. 2013. Linking social anxiety and adolescent romantic relationship functioning: Indirect effects and the importance of peers. Journal of Youth and Adolescence 42 (11): 1708-1720.

Hennig-Thurau, T., K.P. Gwinner, and D.D. Gremler. 2000. Why customers build relationships with companies-and why not. In Relationship Marketing: Gaining Competitive Advantage through
Customer Satisfaction and Customer Retention, ed. Thorsten Hennig-Thurau and Ursula Hansen, 369-391. Berlin: Springer.

Hickinbottom-Brawn, S. 2013. Brand "you": The emergence of social anxiety disorder in the age of enterprise. Theory and Psychology 23 (6): 732-751.

Hinkin, T.R. 1995. A review of scale development practices in the study of organizations. Journal of Management 21 (5): 969-988.

Holt, D.B. 2002. Why do brands cause trouble? A dialectical theory of consumer culture and branding. Journal of Consumer Research 29 (1): 70-90.

Hoover, M.A., and D.C. Richardson. 2008. When facts go down the rabbit hole: Contrasting features and objecthood as indexes to memory. Cognition 108 (2): 533-542.

Huang, C., and R. Guo. 2021. The effect of a green brand story on perceived brand authenticity and brand trust: The role of narrative rhetoric. Journal of Brand Management 28 (1): 60-76.

Huertas, A., M.I. Miguez-Gonzales, and N. Lozano-Monterrubio. 2017. YouTube usage by Spanish tourist destinations as a tool to communicate their identities and brands. Journal of Brand Management 24 (3): 211-229.

Hughes, C., V. Swaminathan, and G. Brooks. 2019. Driving brand engagement through online social influencers: An empirical investigation of sponsored blogging campaigns. Journal of Marketing 83 (5): 78-96.

Innovate 2020. In 2020 YouTube advertising attracts all sorts of brands and vertical. Oculu. http://www.innovatemedia.com/ news/in-2020-youtube-advertising-attracts-all-sorts-of-brandsand-verticals/.

Jang, H., L. Olfman, I. Ko, J. Koh, and K. Kim. 2008. The influence of on-line brand community characteristics on community commitment and brand loyalty. International Journal of Electronic Commerce 12 (3): 57-80.

Jiao, Y., M. Jo, and E. Sarigollu. 2017. Social value and content value in social media: Two paths to psychological well-being. Journal of Organizational Computing and Electronic Commerce 27 (1): 3-24.

Johnson, R.E., C. Selenta, and R.G. Lord. 2006. When organizational justice and the self-concept meet: Consequences for the organization and its members. Organizational Behaviour and Human Decision Processes 99 (2): 175-201.

Juyoen, H., J.F. Smith, K.A. DeYoung, A.S. Anderson, J. Kuang, H.C. Kim, R.M. Tillman, M. Kuhn, A.S. Fox, and A.J. Shackman. 2020. Anxiety and the neurobiology of temporally uncertain threat anticipation. Journal of Neuroscience 40 (41): 7949-7964.

Karahanna, E., S. Xu, and X. Zhang. 2015. Psychological ownership motivation and use of social media. Journal of Marketing Theory and Practice 23 (2): 185-207.

Keller, K.L. 2003. Brand synthesis: The multidimensionality of brand knowledge. Journal of Consumer Research 29 (4): 595-600.

Keller, K.L., and D.R. Lehmann. 2006. Brands and branding: Research findings and future priorities. Marketing Science 25 (6): 740-759.

Kierkegaard, S. 1957. The concept of dread. Princeton, NJ: Princeton Universty Press.

Kucharska, W., I. Confente, and F. Brunetti. 2020. The power of personal brand authenticity and identification: Top celebrity players' contribution to loyalty toward football. The Journal of Product and Brand Management 29 (6): 815-830.

Kucuk, S.U. 2019. Consumer brand hate: Steam rolling whatever I see. Psychology \& Marketing 36 (5): 431-443.

Laudan, L. 1977. Progress and its Problems: Toward a theory of scientific growth. Berkeley, CA: University of California Press. 
Lee, J.E., and B. Watkins. 2016. YouTube vloggers' influence on consumer luxury brand perceptions and intentions. Journal of Business Research 69 (12): 5735-5760.

Lu, Y., J. Lo, and M. Lam. 2020. The blurred boundaries of social media: Can social media interactivity reduce work exhaustion? E Journal of Social and Behavioural Research in Business 11 (3): 2-22.

MacInnis, D.J., and V.S. Folkes. 2017. Humanizing brands: When brands seem to be like me, part of me and in a relationship with me. Journal of Consumer Psychology 27 (3): 355-374.

Malik, A., A. Dhir, P. Kaur, and A. Johri. 2020. Correlates of social media fatigue and academic performance decrement: A large cross-sectional study. Information Technology and People 34 (2): 557-580

Miles, M., M. Huberman, and J. Saldana. 2014. Qualitative Data Analysis, 3rd ed. Thousand Oaks: Sage.

Milfeld, T., and D.J. Flint. 2021. When brands take a stand: The nature of consumers' polarized reactions to social narrative videos. The Journal of Product and Brand Management 30 (4): 532-548.

Mims, C. 2007. Second Life chairman's stump speech takes us down the rabbit hole. Scientific American Observations, June 29. blog. sciam.com/index.php?title=second_life_chairman_s_stump_ speech_take $\&$ more $=1 \& \mathrm{c}=1 \& \mathrm{tb}=1 \& \mathrm{pb}=1$.

Miranda, S., P. Cunha, and M. Duarte. 2021. An integrated model of factors affecting consumer attitudes and intentions towards youtuber-generated product content. Review of Managerial Science 15 (1): $55-73$.

Moulard, J.G., R.D. Raggio, and J.A.G. Folse. 2021. Disentangling the meanings of brand authenticity: The entity-referent correspondence framework of authenticity. Journal of the Academy of Marketing Science 49: 96-118.

Murphy J.M. 1992. What Is Branding? In Branding: A Key Marketing Tool, ed. Murphy J.M. . London: Palgrave Macmillan.

Mushroomnetworks. 2020. https://www.mushroomnetworks.com/infog raphics/youtube---the-2nd-largest-search-engine-infographic/.

Mutsikiwa, M., and T. Maree. 2019. Exploring the brand personalities of Facebook, YouTube, and LinkedIn. International Journal of Internet Marketing and Advertising 13 (4): 285-301.

Omnicore. 2021. YouTube by the numbers: Stats, demographics \& fun facts. https://www.omnicoreagency.com/youtube-statistics/.

Pace, S. 2008. YouTube: An opportunity for consumer narrative analysis? Qualitative Market Research 11 (2): 213-226.

Page, X., P. Wisniewski, B.P. Knijnenburg, and M. Namara. 2018. Social media's have-nots: An era of social disenfranchisement. Internet Research 28 (5): 1253-1274.

Parade, S.H., E.M. Leerkes, and A.N. Blankson. 2010. Attachment to parents, social anxiety, and close relationships of female students over the transition to college. Journal of Youth and Adolescence 39 (2): 127-137.

Podsakoff, P.M., S.N. MacKenzie, J.Y. Lee, and N. Podsakoff. 2003. Common method biases in behavioral research: A critical review of the literature and recommended remedies. Journal of Applied Psychology 88 (5): 879-903.

Reyes, M.E.S., K.F.B.T. Aquino, C.J.O. De Leaon, A.P.P. Munoz, and R.D. Davis. 2021. Me, Myself, and I: Narcissistic personality traits and selfie behavior among selected Filipinos. North American Journal of Psychology 23 (2): 255-271.

Rodebaugh, T.L., R.M. Holaway, and R.G. Heimberg. 2004. The treatment of social anxiety disorder. Clinical Psychology Review 24 (7): 893-908

Roma, P., and D. Aloini. 2019. How does brand-related user-generated content differ across social media? Evidence reloaded. Journal of Business Research 96: 322-339.
Rose G.M., and P. Tadi. 2021. Social anxiety disorder. In StatPearls. Treasure Island, FL: StatPearls Publishing. https://www.ncbi. nlm.nih.gov/books/NBK555890/.

Sashittal, H.C., and A.R. Jassawalla. 2019a. Brand entification as a post-anthropomorphic attribution among Twitter-using Millennials. Marketing Intelligence \& Planning 37 (7): 741-753.

Sashittal, H.C., and A.R. Jassawalla. 2019b. Preliminary evidence of brand acquaintancing on Snapchat. Marketing Intelligence and Planning. 37 (2): 197-210.

Sashittal, H.C., and A.R. Jassawalla. 2020. The personal influence of Instagram bloggers on consumer-brand interactions. Journal of Brand Management 27 (6): 679-690.

Sashittal, H.C., and A.R. Jassawalla. 2014. Why do College Students use Pinterest? A Model and Implications for Scholars and Marketers. Journal of Interactive Advertising 15 (1): 54-66.

Schembri, S., B. Berrilees, and S. Kristiansen. 2010. Brand consumption and narrative of the self. Psychology and Marketing 26 (6): 623-637.

Scitovsky, T. 1992. The Joyless Economy. The psychology of human satisfaction. New York, NY: Oxford University Press.

Smith, A.N., E. Fischer, and C. Yongjian. 2012. How does brandrelated user-generated content differ across YouTube, Facebook, and Twitter? Journal of Interactive Marketing 26 (2): 102-113.

Smith, A.N., and E. Fischer. 2021. Pay attention, please! Person brand building in organized online attention economies. Journal of the Academy of Marketing Science 49 (2): 258-279.

Statista. 2020. Leading YouTube advertisers in the United States in $1^{\text {st }}$ quarter 2020 by impressions. https://www.statista.com/stati stics/1094368/us-youtube-advertisers-ranked-by-impressions/.

Stein, M., and D. Stein. 2008. Social anxiety disorder. The Lancet 371 (9618): 1115-1125.

Stone, M.H. 2017. Dread according to Kierkegaard. International Journal of Psychology and Psychoanalysis 3 (1): 1-8.

Swaminathan, V., K. Page, and Z. Gurhan-Canli. 2007. 'My' brand or 'Our' brand: The effects of brand relationship dimensions and self-construal on brand evaluations. Journal of Consumer Research 34 (2): 248-259.

Swaminathan, V., A. Sorescu, J.B.E.M. Steenkamp, T.C.G. O'Guinn, and B. Schmidt. 2020. Branding in a hyperconnected world: Refocusing theories and rethinking boundaries. Journal of Marketing 84 (2): 24-46.

Tandon, A., A. Dhir, I. Almugren, A.I. Nemer, and G. Naif. 2021. Fear of missing out (FoMO) among social media users: A systematic literature review, synthesis and framework for future research. Internet Research 31 (3): 782-821.

Tellis, G., D.J. MacInnis, S. Tirunillai, and Y. Zhang. 2019. What drives virality (sharing) of online digital content? The critical role of information, emotion and brand prominence. Journal of Marketing 83 (4): 1-20.

Thanh-Thao, N., and B. Grohmann. 2020. The influence of passion/ determination and external disadvantage on consumer responses to brand biographies. Journal of Brand Management 27 (4): $452-465$.

Thomson, M., D.J. MacInnis, and W.C. Park. 2005. The ties that bind: Measuring the strength of consumers' emotional attachments to brands. Journal of Consumer Psychology 15 (1): 77-91.

Torelli, C.J., and R. Ahluwalia. 2012. Extending culturally symbolic brands: A blessing or a curse? Journal of Consumer Research 38 (5): 933-947.

Twenge, J.M. 2013. Does online social media lead to social connection or social disconnection? Journal of College and Character 14 (1): 11-20. https://doi.org/10.1515/jcc-2013-0003.

Vander Shee, B.A., J. Peltier, and A.J. Dahl. 2020. Antecedent consumer factors, consequential branding outcomes and measures of online consumer engagement: Current research and future 
directions. Journal of Research in Interactive Marketing 14 (2): 239-268.

Verhellen, Y., N. Dens, and P. De Pelsmacker. 2013. Consumer responses to brands placed in YouTube movies: The effect of prominence and endorser expertise. Journal of Electronic Commerce Research 14 (4): 287-303.

Warren, C., R. Batra, S.M.C. Loureiro, and R.P. Bagozzi. 2019. Brand coolness. Journal of Marketing 83 (5): 36-56.

Watson, J.C., E.A. Prosek, and A. Giordano. 2020. Investigating psychometric properties of social media addiction measures among adolescents. Journal of Counseling and Development 98 (4): 458-466.

Yanamandram, V., and L. White. 2010. Are inertia and calculative commitment distinct constructs: An empirical study in the financial sector. International Journal of Bank Marketing 28 (7): 569-584.

Yang, H., K. Sanders, and C.P. Bumatay. 2012. Linking perceptions of training with organizational commitment: The moderating role of employees' self-construal. European Journal of Work and Organizational Psychology 21 (1): 125-149.

Zamorski, M.A., and R.K. Ward. 2000. Social anxiety disorder: Common, disabling, and treatable. Journal of American Board Family Practice 13 (4): 251-260.

Zarantonello, L., S. Romani, S. Grappi, and R.P. Bagozzi. 2016. Brand hate. The Journal of Product and Brand Management 25 (1): $11-25$.

Zsila, A., L.E. McCutcheon, and Z. Demetrovics. 2018. The association of celebrity worship with problematic Internet use, maladaptive daydreaming, and desire for fame. Journal of Behavioral Addictions 7 (3): 654-664.

Publisher's Note Springer Nature remains neutral with regard to jurisdictional claims in published maps and institutional affiliations. 